\title{
KUHN, VALUES AND ACADEMIC FREEDOM
}

\author{
Howard SANKEY
}

\begin{abstract}
For Kuhn, there are a number of values which provide scientists with a shared basis for theory-choice. These values include accuracy, breadth, consistency, simplicity and fruitfulness. Each of these values may be interpreted in different ways. Moreover, there may be conflict between the values in application to specific theories. In this short paper, Kuhn's idea of scientific values is extended to the value of academic freedom. The value of academic freedom may be interpreted in a number of different ways. Moreover, there are other values which play a role in the functioning of our academic institutions. As with the possible conflict between scientific values, there may be conflict among the academic values.
\end{abstract}

KEYWORDS: Thomas S. Kuhn, values, theory-choice, academic freedom

\section{Introduction}

Thomas S. Kuhn was an influential contributor to the history and philosophy of science. He might well be regarded as one of the founders of that interdisciplinary area of study. Kuhn is best-known for The Structure of Scientific Revolutions, which introduced the idea of scientific paradigms, and proposed a model of revolutionary scientific change. ${ }^{1}$ In his less well-known book, The Essential Tension, Kuhn offered insight into the nature of scientific values that may be relevant to current discussion of academic freedom. ${ }^{2}$ Kuhn's insights into scientific values apply to the domain of scientific theory-choice. But they have interesting application to the question of academic freedom.

\section{The Role of Values in Theory-Choice}

Kuhn provoked the ire of philosophers of science who took him to defend an irrationalist conception of the choice between competing scientific theories. $\mathrm{He}$ compared the choice between such competing theories (or paradigms) as geocentric and heliocentric astronomy or phlogistic and oxygen chemistry to a shift of visual

${ }^{1}$ Thomas S. Kuhn, The Structure of Scientific Revolutions, $4^{\text {th }}$ ed. (Chicago: University of Chicago Press, 2012).

${ }^{2}$ Thomas S. Kuhn, The Essential Tension (Chicago: University of Chicago Press, 1977).

LOGOS \& EPISTEME, XII, 4 (2021): 463-467 
Howard Sankey

gestalt. He likened the intellectual process that a scientist goes through in making such a choice to a religious conversion experience. He argued that scientific observation is so laden by theory that it is as if scientists in competing paradigms live in different worlds. When they look at the same object, they do not see the same thing.

Kuhn was taken aback by the philosophical criticism of the views he had proposed in Structure. In a chapter of The Essential Tension, Kuhn sought to assuage the philosophical ire by affirming that his views were less iconoclastic than had been thought. ${ }^{3}$ There is a shared set of criteria which scientists employ in the appraisal of competing theories. The criteria guide scientists in their choice of theory. These criteria, which Kuhn describes as 'values,' include accuracy, breadth, consistency, simplicity and fruitfulness. Kuhn described the criteria as values because they do not function as rules which dictate or determine the choice of theory. Rather, they are values, which inform and provide guidance, but do not dictate an outcome.

Kuhn made two points about the nature of these scientific values which are of possible relevance to contemporary discussion of academic freedom. First, Kuhn pointed out that even though scientists may share a commitment to a specific value, such as simplicity, they might not understand that shared value in the same way. Simplicity might, for example, be understood as ease of calculation or as involving the postulation of as few entities as possible to explain a phenomenon. Second, Kuhn pointed out that there might be conflict between the values, so that scientists equally committed to the same set of values might diverge with respect to which value they emphasize the most. Simplicity, Kuhn suggested, might favor one theory, while accuracy or breadth of application might favor another.

\section{Academic Freedom as Value}

Kuhn's suggestions about the values that guide scientific theory-choice may appear to have nothing whatsoever to do with academic freedom. But it is his points about the interpretation of the values and the potential for conflict between them that may have some bearing on the topic of academic freedom. For academic freedom is a cherished value of academic institutions. It might be understood in various ways. And it might conflict with other values that are also deemed important.

There are numerous values that operate within our universities and other academic institutions. The freedom to conduct one's research in a way not constrained by political or other pressure is one such value. The value of truth as an aim of inquiry is another value. Scholarly values, such as the norms that govern the

${ }^{3}$ See Kuhn, The Essential Tension, 321-4. 
collection, handling and interpretation of evidence provide examples of other values that apply in an academic context. There are also ethical considerations that apply, for example, to experimentation on animals or to the way in which research may be conducted on human beings.

Without attempting to exhaustively catalogue the values that apply in an academic setting we can see already that there is a multitude of such values. How are these to be understood? I have mentioned the value of being able to conduct one's research in a way that is not constrained by political pressure. One might think of that as the value of academic freedom. But equally, one might attempt to articulate the value of academic freedom in some other way, such as the freedom to express one's ideas in a public forum without fear of censure. Or, perhaps, it is a simple matter of being able to choose what one teaches in the classroom.

Here we see Kuhn's point about the multiple understandings of a single value. Academic freedom may be understood in different ways. What about Kuhn's other point about the tension between values? A scientist-colleague once complained to me that his proposal to surgically implant a second heart into an experimental lab rat had been blocked by the ethics committee. The ethical requirement to not unduly cause harm to an animal had been taken to outweigh that scientist's curiosity as to what might happen once the rat had two functioning hearts in its chest. It is tempting to say that this is a case in which the value of unconstrained inquiry has run into a competing value about not causing undue harm to animals. No doubt, there are many further sources of potential conflict between the values that run through our academic institutions.

In extending Kuhn's point to academic values, I am broadening the sense of the term 'value' beyond the sense in which Kuhn employed the term. For Kuhn, the scientific values were criteria of theory-choice which scientists use in their appraisal of theories and as the basis of their choice between theories. In extending Kuhn's point to academic values in general I am speaking about a broad range of items that may be of value in an academic context. Some, such as the norms governing the use of evidence, may be analogous to or even identical with criteria of theory-choice. But, other things, such as freedom of inquiry, the aim of truth and ethical constraints on research are values in another sense. They are not criteria of theory-choice. But I think this extension and broadening is warranted. It is warranted because, like the academic values, the properties of theories picked out by the scientific values are properties on which significant value is placed. Kuhn's scientific values and the academic values are both values in this broader sense. 
Howard Sankey

\section{The Upshot}

Kuhn offered his remarks about the role of scientific values in theory-choice in response to philosophical critics who accused him of making theory-choice irrational, a matter of religious conversion. He was, I think, attempting to tell us about the nature of scientific rationality. It is not a matter of knockdown argument and conclusive proof. Choice of theory is a deliberative process in which multiple competing considerations must be weighed. Even though scientists may in the end agree in their choice of theory, they need not. And, if they do agree, they need not do so on the basis of the same considerations. Much weighing up and balancing of potentially competing considerations is involved. Rational choice of theory requires deliberative judgement rather than following a clear and simple set of rules.

Kuhn was wont to describe the situation by saying that there is no "neutral algorithm of theory-choice." ${ }^{4}$ It is not a matter of following a set of rules which will mechanically determine a single fixed outcome that all scientists will accept. This was one of the reasons that Kuhn described the shared criteria of theory-choice as values rather than as rules. They guide and inform scientific decisions but may not dictate unique outcomes.

What is the relevance of Kuhn's insight into the values that govern theorychoice to the issue of academic freedom? We might recognize that academic freedom is one among a number of values with which academic life is imbued. It is not the only such value. It may be understood in different ways, and it may conflict with other values. But, in the same way that the multiplicity of scientific values tells us something informative about scientific rationality, the multiplicity of academic values tells us something informative about academic life. There is no need for despair. That is how the institution works.

Perhaps one might agree in general but demur on a point of detail. Surely, some values are the most fundamental of all academic values. Perhaps the value of freedom to pursue one's inquiries unhampered by external constraint might be taken as the most fundamental of the academic values. But this would be like taking one of Kuhn's scientific values as the single most important value. You can do that, and you could set up an algorithm, such that a unique outcome of theory-choice is ensured. But, if you do that, you set up one value as sacrosanct, and you beg the question against the other values. It is not clear that much will be gained by attempting to set up one value as the supreme academic value that outweighs all others. And something might be lost. After all, what brings energy and life to

\footnotetext{
${ }^{4}$ Kuhn, Structure, 198.
} 
Kuhn, Values and Academic Freedom academic discussion is often the fact that a myriad different thoughts and approaches engage in vibrant interplay as we explore and develop our ideas and those of others. 


\section{University Library}

\section{- M M I N E R VA A gateway to Melbourne's research publications}

Minerva Access is the Institutional Repository of The University of Melbourne

Author/s:

Sankey, $\mathrm{H}$

Title:

Kuhn, values and academic freedom

Date:

2021

Citation:

Sankey, H. (2021). Kuhn, values and academic freedom. Logos and Episteme: an international journal of epistemology, 12 (4), pp.463-467. https://doi.org/10.5840/LOGOSEPISTEME202112436.

Persistent Link:

http://hdl.handle.net/11343/297311 